\title{
Silver Nitrate Cauterization for Anal Fistulas with High Blind Tract Chemical Therapy in Complicated Anal Fistulas
}

\author{
Arif Hakan Demirel, Seyfettin Köklü
}

\section{ABSTRACT}

Aim: The efficiency of a chemical cauterization technique in the treatment of high blind tracts, which are important causes of recurrence in anorectal fistula, were investigated.

Materials and methods: Fifteen patients underwent surgery for low perianal fistula with high blind tracts. Partial fistulectomy and cutting seton technique was performed on all patients. The high blind tracts were cauterized by silver nitrate particles and the surgical area was left for secondary healing. The follow-up duration was 6 months to 1 year. The anal continence was evaluated according to the Wexner score.

Results: Four of the 15 patients were female, whereas 11 were male. Ages ranged between 17 and 67 years. While 11 participants were primary cases, four were recurrent. Nine of the fistula tracts were intersphincteric and five were transsphincteric and one case had horseshoe fistula. The mean wound healing duration was 5.5 weeks. Mild anal incontinence (Wexner score $=3$ ) was recorded in one case and recurrence was observed in another.

Conclusion: Cauterization with silver nitrate is a new treatment method for high blind tract in anal fistulas. It is a safe and noninvasive method that reduces recurrences and surgical complications.

Keywords: Fistula-in-ano, Surgery, Silver nitrate.

How to cite this article: Demirel $A H$, Köklü S. Silver Nitrate Cauterization for Anal Fistulas with High Blind Tract Chemical Therapy in Complicated Anal Fistulas. Euroasian J HepatoGastroenterol 2013;3(1):49-53.

Source of support: $\mathrm{Nil}$

Conflict of interest: None

\section{INTRODUCTION}

Although perianal fistula is one of the oldest diseases that have ever been known, its curative treatment has not been standardized yet. Recurrence and anal incontinence in perianal fistulas are the most important problems of surgical treatment. ${ }^{1}$ The most significant factors causing recurrence are the poor detection of all tracts, and overlook the ascending component of fistula, named high blind tract or blind sinus. In the present study, the preliminary results regarding the usage of silver nitrate in the treatment of anal fistulas with high blind tract is introduced.

\section{MATERIALS AND METHODS}

Fifteen consecutive cases underwent surgery for low perianal fistula with high blind tracts at the 2nd Surgery Clinic of M inistry of $\mathrm{H}$ ealth A nkara Training and R esearch
Hospital. Of the 15 patients, four (26.7\%) were female and $11(73.4 \%)$ were male. The ages ranged between 17 and 67 years, and the mean was 40.1 years. The symptom duration was changing from at least 1 month to 20 years. The most encountered symptoms were discharge from the fistula orifice $(93.3 \%)$, pain in the anal region (46.7\%), and pruritus (13.3\%). Flatulence from the fistula's external orifice was reported in one case $(6.7 \%)$. All of the cases had a history of anal pyogenic abscess, which was either surgically or spontaneously drained. A total of four patients $(26.7 \%)$ had previously undergone a surgical procedure for anal fistula, whereas $11(73.4 \%)$ were primary cases. One of the secondary cases had undergone fistulectomy and seton procedure in our clinic, but fistula was repeated due to the accidental rupture of the seton; high blind tract had not been detected during the first procedure. The remaining three secondary cases had undergone surgery at different hospitals and also had recurred. No information could be obtained regarding their surgical technique.

In order to discover additional intestinal pathology, rectosigmoidoscopy was performed preoperatively. Patients were postoperatively followed up for at least 6 months. A nal continence of patients was evaluated by Wexner verbal score. In addition digital rectal examination was performed for evaluation of the anal continence of patients on follow-up duration.

\section{Surgical Technique}

All patients, who were not given any food one night prior to the surgery, received enema in the morning. In the operating room patients were placed in the lithotomy position, and injected with $1 \mathrm{gm}$ cefazolin at the beginning of the anesthesia. Spinal anesthesia was performed to 10 patients and general anesthesia was performed to three patients and pudendal block was performed to two patients.

The localization and height of the internal orifice of the fistula was determined by injecting methylene blue through the external orifice. The fistula tract was established via a flexible probe and dissection was performed approximately $3 \mathrm{~mm}$ around the fistula by using an electrocautery. When the external sphincter was visible, the dissection was terminated and the dissected section including distal part of the fistula was removed. A rubber seton which is disinfected with Cidex solution was placed within the 
proximal region of the fistula, which includes the internal orifice, and the internal sphincter and the external sphincter. A circle was made by binding the free ends of the seton to each other (Fig. 1).

The blind tracts, which extend within the intersphincteric area up to the levator ani muscle, can be visualized during the dissection of the tissue since they are stained by methylene blue. A fterwards, their direction and depth are also determined via a probe. Chemical cauterization via silver nitrate stick particles was applied to all of the 15 cases. A pproximately $2 \times 2 \mathrm{~mm}$ diameter small particles cut from silver nitrate sticks were placed within the depth of the blind tract with a forceps for 2 to 3 minutes period. A ccording to the diameter and the depth of the tract, 2 to 4 silver nitrate particles were used during this procedure (Figs 2 and 3 ). Then debridement of the granulation tissue was made by curette. Subsequently, the curetted blind ascending tract was washed up by applying 20 to $30 \mathrm{ml}$ saline with an injector. The wound was left for secondary healing. In cases with a skin wound defect larger than $5 \mathrm{~cm}$, the wound sides were narrowed by 0 no propylene sutures. Patients were discharged
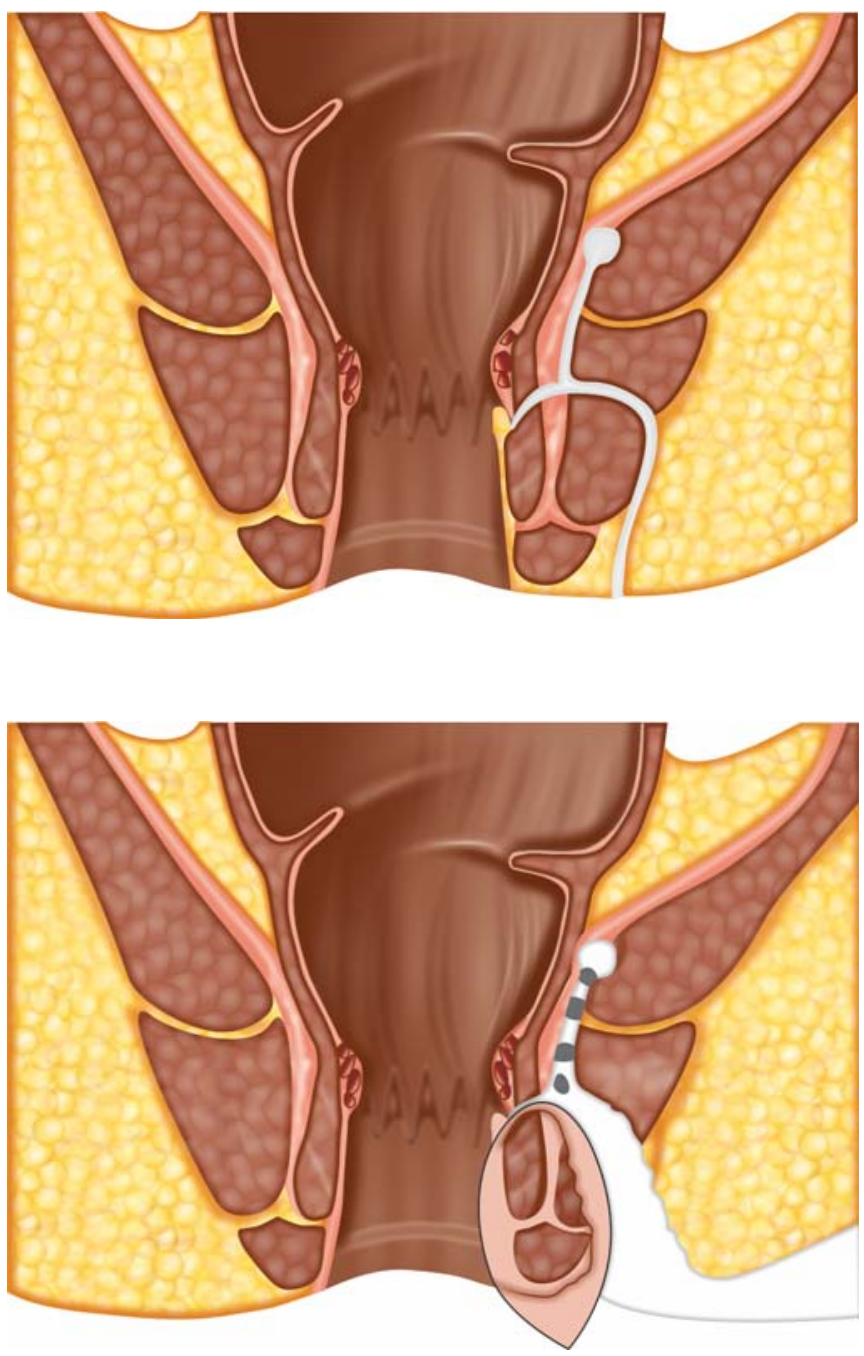

Fig. 1: Dissection of fistula region on first postoperative day, and administered $3 \times 500 \mathrm{mg}$ methimazole for 2 days for analgesia and $2 \times 500 \mathrm{mg}$ ciprofloxacin for 7 days, along with daily seating bath with betadine.

In order to narrow seton circles, patients were called to clinic for control examination at weekly intervals. This procedure was performed by silk ties after applying $4 \mathrm{gm}$ lidocaine intrasphincterically.

\section{RESULTS}

When the cases were evaluated according to the type of the fistula, eight (53.3\%) had intersphincteric, whereas six $(40 \%)$ had trans-sphincteric and one $(6.7 \%)$ had horseshoe fistula. Of the recurrent cases, three were trans-sphincteric and one was intersphincteric. All of the fistulas were low subtype and had high blind tracts in ascending localization. The total external orifice number, detected in 15 cases, was 21; being single in 10 cases (66.7\%), and multiple in five $(33.3 \%)$. The external orifices were mostly located at 7 to $9 o^{\prime}$ clock direction in lithotomy position.

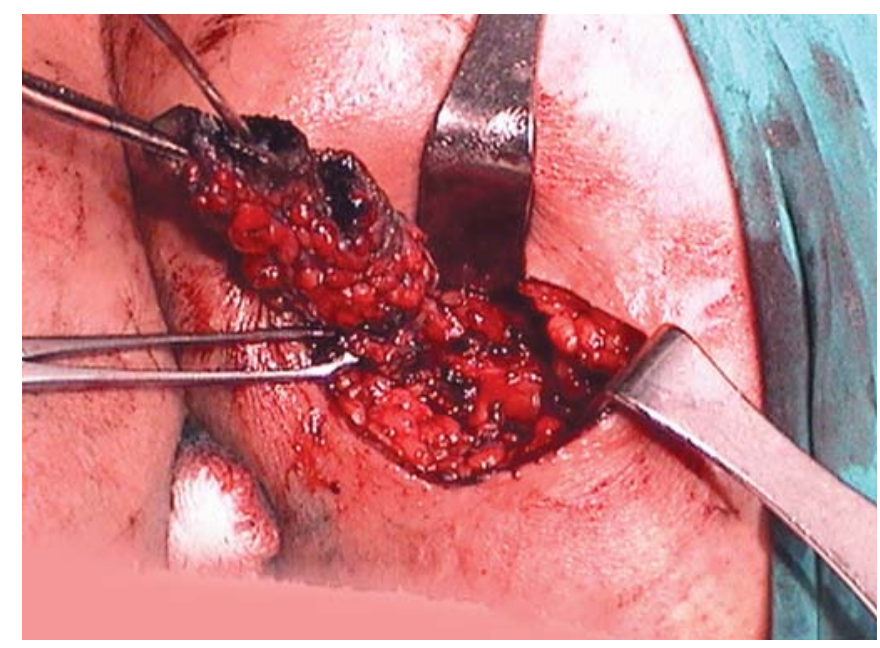

Fig. 2: Operational procedure

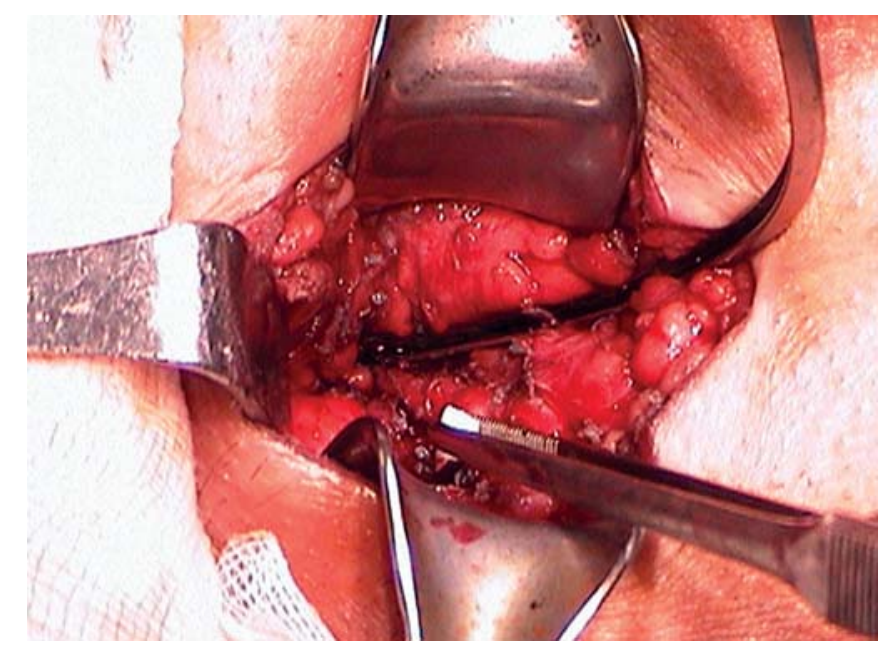

Fig. 3: A view of cauterization 
The average breaking time of the seton was 4.4 weeks (3-6 weeks). The mean wound healing duration was 5.5 weeks (4-8 weeks) in all cases other than recurred one. $\mathrm{Neither} \mathrm{systemic} \mathrm{nor} \mathrm{local} \mathrm{complications} \mathrm{occurred}$ subsequent to silver nitrate cauterization. Recurrence was recorded in one $(6.7 \%)$ of the patients. In this case partial fistul ectomy and cutting seton for a trans-sphincteric fistula had been performed. At the end of the postoperative 3rd week the cutting seton was removed. During the 6 th week examination, it was observed that the wound had almost completely closed, and a purulent fluid was leaking from the center of the epithelized wound. The case that did not respond to the debridement and dressing was considered as a recurrence. In the other patient partial fistulectomy and cutting seton had been performed for a trans-sphincteric fistula. The cutting seton was removed at the end of the postoperative 6th week, and the wound surface has epithelized after 2 weeks. At the end of the postoperative 3rd month, a superficial subcutaneous sinus with minimal leakage was observed on the surgical scar. This sinus was closed postoperative 6th month spontaneously. We did not evaluate this case a recurrence.

Temporary anal incontinence was established in one case. Thirty-one years old male patient who had previously undergone a surgical procedure for anal fistula complained incontinence of gas and liquid postoperatively. However, his initial Wexner score (11 at the beginning) became 0 at the postoperative 1st year. Second patient who suffered from anal incontinence was 38 years old female in whom two cutting setons were used. She complained incontinence of gas and liquid while coughing and during physical exercise postoperatively. Her Wexner score was 15 initially and became 3 at the end of the 1st year follow-up.

\section{DISCUSSION}

Chronic pyogenic abscesses are the most frequent cause of perianal fistulas. Other causes include tuberculosis, ulcerative colitis, Crohn's disease, trauma, and more rarely, cancers of anal canal and rectum, lymphogranuloma venereum, anorectal actinomycosis, and colon diverticulum. ${ }^{2} \mathrm{M}$ ajority of the perianal fistulas are formed as a result of either spontaneous drainage or insufficient surgical drainage of pyogenic abscesses subsequent to anal gland infections. In the present case series, no disease other than pyogenic perianal abscess was determined as the etiology of the fistula.

The principle of the surgical intervention is to maintain the anal continence and to supply sufficient drainage. We preferred fistulectomy technique, because the high blind tracts, which can be overlooked during the excision of the fistula, can be exposed easily by fistulectomy. In our clinic partial fistulectomy procedure was performed and cutting seton application was added. In this way we aimed to obtain the advantages of two methods and to avoid from anal incontinence.

Some authors suggest the seton method for transsphincteric and extrasphincteric fistulas. This technique is applied in various forms. Drainage seton is used for the drainage of anorectal sepsis; treatment duration is long and the recurrence rate is high (22-56\%). D rainage seton is found to be beneficial in patients with anorectal sepsis related to Crohn's disease and in patients with multiple complicated fistulas. A $n$ endorectal advancement flap may be performed if the rectum is healed from active Crohn's disease. ${ }^{3}$

The cutting seton is a widely used type of technique that is based on cutting the ischemized sphincter muscle in time with the fistula tract fibrosis. The recurrence rate of this technique is reported between 0 and $18 \% .{ }^{4}$ Cutting the upper part of the fistula tract, which includes the internal orifice within the anal canal, in further seances based on the ischemia principle, is a process which is performed in our clinic. Gradual fistulectomy with cutting seton in high level fistulas is reported to be a safe and effective method according to Pearl. ${ }^{5} \mathrm{H}$ owever, in a study conducted by $\mathrm{V}$ an Tets, this procedure was not recommended for high anorectal fistulas due to high rates of anal incontinence. ${ }^{6}$ In the present study all of the fistulas were low subtype, but all of them had high ascending blind tracts. Except one of the patients postoperative permanent anal incontinence was not developed. Only one patient in whom two cutting setons were used had minimal gas incontinence at the end of the present study.

In the K shara method, a chemical seton technique, fistulotomy occurs approximately within 8 weeks via a herbal seton (K shara sutra), which is changed weekly. The recurrence rate of this technique is reported as 0 to $4 \% .^{7,8}$ A mong irritating chemical substances, 3 to $4 \%$ silver nitrate, bismuth alloy, and quinine-urethane, have been locally applied within the fistula tract since the end of the 19th century. ${ }^{7}$

Some noninvasive methods in fistula treatment were been suggested. The application of cyanoacrylate glue and acellular extracellular matrix plug were claimed as an alternative methods to surgery in patients suffering from fistula-in-ano as a safe and a noninvasive methods. ${ }^{9}$ In addition, expanded adipose-derived stem cells were used for the treatment of complex perianal fistula in a phase II clinical trial. ${ }^{10}$ The early outcomes of the ligation of fistula tract (LIFT) at the intersphincteric area for fistula-in-ano surgery, which aims at total anal sphincter preservation 
presented as a safe and easy tecnique. However, results of this study with long-term evaluation have not been obtained. ${ }^{11,12}$

The solid form of silver nitrate is used for chemical cauterization and antisepsis in the treatment of epistaxis and neonatal umbilical granulomas, whereas the solution form is widely used for prophylaxis of neonatal conjunctivitis. ${ }^{13-17}$ The solution form of silver nitrate is also used for filarial chyluria in urology. ${ }^{18,19}$ In addition, the solid form of silver nitrate has been found to be successful in the treatment of wart and nail granulomas and oral aphthous stomatitis. ${ }^{20-22}$ It is reported that the silver nitrate rods are successfully applied for the cauterization of genital Bartholin cysts; the silver nitrate particles are left within the cyst, as in the present study, and debrided after 48 hours. ${ }^{23-25}$ In our cases, curettage was performed 1 minute after the application, and then the debris and the chemical residues were washed with saline. The pleurodesis formation effect of silver nitrate during thoracic surgery has been found to be better than the talk powder, and its efficacy in bronchopleural fistulas has been investigated as well. ${ }^{26,27}$ Silver nitrate was used in three cases for endoscopic cauterization of the tracts; the gastrocutaneous fistulas developed after removal of the gastrostomy tubes were closed by clips. ${ }^{28}$

Bleeding, anal stricture, recurrence of the fistula, and anal incontinence are the most frequent complications in the surgical treatment of anorectal fistulas. The risk of bleeding is particularly high in deep ischiorectal fistulas. Since there is no need to conduct a high level tissue dissection for the excision of ascending components with the introduced silver nitrate cauterization technique, the risk of bleeding is minimized. In this study group, the expected complications, such as perioperative bleeding and anal stricture, were not encountered.

Recurrence is inevitable in fistulas that are insufficiently excised and drained. Recurrence is particularly related to the ascending components of the fistula tract, which are either not exposed after the surgery or neglected during treatment. Complicated type fistulas, failure to find the internal orifice, secondary cases, and surgeon experience have been found to be associated with recurrences, whereas the types of the surgical procedure, female gender, and high fistulas have been found to be associated with incontinence in a study investigating the recurrences and the incontinence in the surgery of anal fistula. ${ }^{29}$ In the present study, the recurrence which observed in one of the cases could be explained by early closure of the incompletely drained wound after early seton removal. The mild anal incontinence in a patient could be due to her gender tendency and the presence of multiple fistula tracts. Hence, we believe that anal incontinence was not related to the application of silver nitrate in that case.

In the present study, a new method for the surgical treatment of anorectal fistulas and its preliminary results were introduced. We conclude that, if the high blind tract of the anal fistula which is important source of recurrence cannot be excised due to the high location or compact fibrosis, application of silver nitrate to the high blind tract and curettage will be an effective method of therapy. This cheap and safety method would lessen the surgical complications and recurrences.

\section{REFERENCES}

1. Gordon PH. A norectal abscesses and fistula in ano. In: Gordon $\mathrm{PH}, \mathrm{N}$ ivatvongs $\mathrm{S}$ (Eds). Principles and practice of surgery for the colon, rectum and anus (2nd ed). M issouri: Q uality M edical Publishing 1999:241-86.

2. Goligher J. Fistula in ano. In: Goligher J (Ed). Surgery of the anus, rectum and colon (5th ed). London: Bailliere $\&$ Tindall 1984:178-220.

3. B runicardi FC. Colon, rectum, anus. In: Bullard KM, Rothenberger DA (Eds). Scwartz's principles of surgery (8th ed). Singapore: M cG raw-Hill B ook Company 2004:1055-117.

4. Goldberg SM, Garcia-A guilar J. The cutting seton. In: Phillips RKS, Lunniss PJ (Eds). A nal fistula: Surgical evaluation and management (2nd ed). L ondon: Chapman \& Hall 1996:95-102.

5. Pearl RK, A ndrews J R, Orsoy $C P$, et al. R ole of the seton in the management of anorectal fistulas. Dis Colon Rectum 1993;36:573-79.

6. V an Tets W F, K uijpers JH. Seton treatment of perianal fistula with high anal or rectal opening. BrJ Surg 1995;82:895-97.

7. Rangabashyam N. M anagement by chemical seton. In: Phillips RK S, L unniss PJ (Eds). A nal Fistula: Surgical evaluation and management (2nd ed). Chapman \& Hall, London 1996:103-05.

8. M ohite JD, Gawai RS, Rohondia OS, B apat RD. K sharsootra (medicated seton) treatment for fistula-in-ano. Indian J Gastroenterol 1997;16:96-97.

9. Jain SK, Kaza RC, Pahwa M, B ansal S. R ole of cyanoacrylate in the management of low fistula in ano: A prospective study. Int J Colorectal Dis 2008;23:355-58.

10. Garcia-OImo D, H erreros D, Pascual I, et al . Expanded adiposederived stem cells for the treatment of complex perianal fistula: A phase II clinical trial. Dis Colon Rectum 2009;52:79-86.

11. Rojanasakul A, Pattanaarun J, Sahakitrungruang C, Tantiphlachiva K. Total anal sphincter saving technique for fistula-in-ano; the ligation of intersphincteric fistula tract. J M ed A ssoc Thai 2007:90:581-86.

12. Shanwani $A, N$ or $A M, A$ mri N . Ligation of the intersphincteric fistula tract (LIFT): A sphincter-saving technique for fistula-inano. Dis Colon Rectum 2010;53:39-42.

13. V an Hasselt P, Gudde H. Randomized controlled trial on the treatment of otitis externa with one percent silver nitrate gel. J Laryngol Otol 2004;118:93-96.

14. Toner JG, Walby AP. Comparison of electro and chemical cautery in the treatment of anterior epistaxis. J Laryngol Otol 1990;104:617-18. 
15. Pallin DJ, Chng YM, M CK ay MP, et al. Epidemiology of epistaxis in US emergency departments, 1992 to 2001 Ann Emerg M ed 2005;46:77-81.

16. Meltzer DI. A newborn with an umbilical mass. Am Fam Physician 2005;71:1590-92.

17. Brussieux J, Boisivon A, Théron HP, et al. Prevention of neonatal conjunctivitis. A comparative clinical and bacteriologic study of 2 eyedrops: Silver nitrate and oxytetracycline chlorhydrate. A nn Pediatr (Paris) 1991;38:637-41.

18. Dalela D, Rastogi $M, G$ oel $A$, et al. Silver nitrate sclerotherapy for 'clinically significant' chyluria: A prospective evaluation of duration of therapy. U rol Int 2004;72:335-40.

19. Nandy PR, D wivedi US, V yas N, et al. Povidone iodine and dextrose solution combination sclerotherapy in chyluria. U rology 2004; 64:1107-09.

20. Y azar S, Basaran E. Efficacy of silver nitrate pencils in the treatment of common warts. J Dermatol 1994;21:329-33.

21. Erdogan FG. A simple, pain-free treatment for ingrow $n$ toenails complicated with granulation tissue. Dermatol Surg 2006;32:1388-90.

22. Alidaee M R, Taheri A, M ansoori P, Ghodsi SZ. Silver nitrate cautery in aphthous stomatitis: A randomized controlled trial. BrJ Dermatol 2005;153:521-25.

23. YuceK, Zeyneloglu HB, Bukulmez O, K isnisci HA. O utpatient management of $B$ artholin gland abscesses and cysts with silver nitrate. A ust N Z J Obstet Gynaecol 1994;34:93-96.

24. Kafali $\mathrm{H}, \mathrm{Y}$ urtseven $\mathrm{S}, \mathrm{O}$ zardali I. A spiration and alcohol sclerotherapy: A novel method for management of Bartholin's cyst or abscess. Eur J Obstet Gynecol Reprod Biol 2004;112: 98-101.
25. M ungan $T$, $U$ gur $M, Y$ alcin $H$, et al. Treatment of B artholin's cyst and abscess: Excision versus silver nitrate insertion. Eur J Obstet Gynecol Reprod Biol 1995;63:61-63.

26. Paschoalini $M$ da $S, V$ argas $F S, M$ archi $E$, et al. Prospective randomized trial of silver nitrate vs talc slurry in pleurodesis for symptomatic malignant pleural effusions. Chest 2005; 128:684-89.

27. Lois M, Noppen M. B ronchopleural fistulas: An overview of the problem with special focus on endoscopic management. Chest 2005; 128:3955-65.

28. Teitelbaum JE, Gorcey SA, Fox VL. Combined endoscopic cautery and clip closure of chronic gastrocutaneous fistulas. Gastrointest Endosc 2005;62:432-35.

29. Garcia-A guilar J, Belmonte C, Wong WD, et al. A nal fistula surgery. Factors associated with recurrence and incontinence. Dis Colon Rectum 1996;39:723-29.

\section{ABOUT THE AUTHORS}

\section{Arif Hakan Demirel}

Associate Professor, Department of General Surgery, M inistry of Health, A nkara Training and Research Hospital, A nkara, Turkey

Correspondence Address 12 Cad, 379 Sok, No: 16/19, Sayistay Sit., Demetevler, Ankara-06200, Turkey, Phone: +90-3125953423 Fax: +90-3123633396, e-mail: ahakandemirel@ hotmail.com

\section{Seyfettin Köklü}

A ssociate Professor, Department of G astroenterology, U niversity of Hacettepe, A nkara, Turkey 